\title{
Wood and Bamboo Fiber Combination in the Production of Poly Lactic Acid (PLA) composite
}

\author{
Reni Mulyani ${ }^{1}$, Lisman ${ }^{2}$, Hadi Kusumah ${ }^{3}$, and Rahayu ${ }^{4}$ \\ ${ }^{1,4}$ Chemistry, Muhammadiyah University Sukabumi, west java, Indonesia \\ ${ }^{2}$ Biomaterials Research and Developmen-LIPI, Bogor, West java, Sukabumi \\ ${ }^{3}$ Civil engineering, Muhammadiyah University Sukabumi, west java, Indonesia
}

\begin{abstract}
Bio-composite made from a combination of natural fibers such as wood fiber (wood hard or soft) or other fibers (fiber grain, flax, sisal and hemp) in a polymer matrix. In this study, natural fibers such as cellulose synthesized from Meranti wood (KM) and Betung bamboo (BB) as a matrix or reinforcement material poly lactic acid (PLA) are biodegradable. Tensile and flexible strength tests carried out using Universal Testing Machine (UTM). Flexible and tensile tests that bio composite Betung bamboo better than Meranti wood. Apparently the flexion strength of the composite KM between $10 \%$ and $20 \%$ there was no significant difference, In contrast to the composition of the bio composite between $10 \%$ and $20 \%$. Flexion strength has height values contained in the bio composite Betung Bamboo $20 \%$ of $57.4054 \mathrm{~N} / \mathrm{mm} 2$. The highest power of elasticity found in the composition of the bio composite Betung bamboo 20\% of 1.95 GPA. Betung bamboo is high strength reinforced silica matrix composite.
\end{abstract}

Keywords: Bio composites, poly lactic acid, Meranti wood, Betung bamboo

\section{Background}

Natural lignin cellulose fibers can be made from wood and non-wood (bamboo, sisal, hemp, etc) is a very abundant material on earth. As the amplifier component in composite materials, natural fibers have advantages over synthetic fibers, among others, it is renewable, recyclable and biodegradable in the environment [1]. Among natural fibers have the good mechanical properties and is cheaper than synthetic fibers. Natural fibers have several drawbacks, especially its weakness absorbs of water, quality is not uniform, and has low stability to heat. Cellulose is an organic compound with the formula $\left(\mathrm{C}_{6} \mathrm{H}_{10} \mathrm{O}_{5}\right) \mathrm{n}$, polysaccharides consisting of a linear chain of several hundred to over ten thousand bond $\beta(1 \rightarrow 4)$ D-glucose units. Cellulose can be produced by chemical treatment. On the study of the chemical treatment is given to extracting solution, the removal of lignin (with sodium chlorate) and removal of hemicellulose with potassium hydroxide solution [2]. The result is pure cellulose with $\alpha$-cellulose content of more than $85 \%$. Poly lactic acid is polyester that can be produced using raw materials of renewable natural resources such as starch and cellulose through lactic acid fermentation. Chemically for produced PLA polymerization of lactic acid can be done in two ways, namely directly of lactic acid and indirectly through lactide former (lactic acid dimmer) in advance and followed by polymerization into PLA. Bio composite is a combination of natural fibers (bio fibers) such as wood fiber (wood hard or soft) or fiber other than wood (grain fiber, hemp, jute, sisal and flax) with a matrix which is usually made of polymers [3]. Based on such understanding, bio fibers is an important component of the bio composite material. This fibrous material is derived from the fiber of trees, plants or shrubs so called bio fibers $[4,5]$. Composite nature or bio fibers currently serves as an alternative material of glass fiber composite. Bio fibers are growing rapidly as an additive in thermoplastic material. Development of the bio composite material is constantly evolving, especially research on the interface (interface) bio composites, bio composite design, fabrication process bio composites and process characterization $[6,7]$.

\section{1 Instrument and Material}

\section{Material and Methods}

Instruments were conducted using oven, stirrer, labo plastomill, UTM, FTIR. The chemical used were PLA LACEA H-280, Meranti wood (KM), Betung bamboo (BB), Sodium Chlorate 25\%, acetic acid, $5 \% \mathrm{KOH}$, ethanol, acetone and distilled water. All Chemical was analytical grade and obtained from Sigma, Esun and Merck.

\subsection{Methods}

Preparation of raw materials sample of wood and bamboo made small pieces and then crushed with a hammer mill and then filtered to obtain wood and bamboo powder with 40-60 mesh size. Preparation of powdered cellulose Fiber is $1.5 \mathrm{~g}$ powder Meranti wood or Betung bamboo with distilled water, sodium chloride and acetic acid, heated in the water bath for one hour at a temperature $80^{\circ} \mathrm{C}$. The process is repeated up to four 
times the replication. Wash with distilled water until a neutral $\mathrm{pH}$ cleaner and then strain. After washing and screening process was added $15 \mathrm{ml}$ of $5 \% \mathrm{KOH}$ and $30 \mathrm{ml}$ of Cellulose fibers and PLA (refer to Table 1) mixed with ethanol for one hour followed by filtration or centrifuge to remove the liquid phase (water and ethanol).

The process is repeated 2 times to replace the water with ethanol, replaced with acetone. Cellulose which has been evaporated dispersed into the solvent acetone. Furthermore, the PLA was added slowly to the dispersion of the cellulose, stirring constantly. After the PLA in acetone, stirring is continued for 2 hours for PLA and cellulose mixed evenly. PLA and the cellulose mixture was then poured into a Teflon-coated tray and dry them for a day at room temperature, followed by vacuum drying at a temperature of $50{ }^{\circ} \mathrm{C}$ for 8 hours and then the mixture was dried and cut into small pieces done bleeding process using various labo plastomill at a temperature of $140{ }^{\circ} \mathrm{C}$ and cooling in the cold press for $3 \mathrm{~min} 0.1 \mathrm{MPa}$. The importance of the film sheets can be used for further testing [1,2]. Bending and tensile tests were measured by Universal Testing Machine (UTM). Results shown are the average values of the five samples. Analyze group function of poly lactic acid bio composites and cellulose fibers from wood and Betung bamboo were characterize analyze by FTIR (Fourier transformation Infrared [8].

Table I. The composition of the composite

\begin{tabular}{|c|c|c|}
\hline Samples & Cellulose(g) & PLA (g) \\
\hline PLA & 0 & 60 \\
\hline $\mathbf{1 0} \mathbf{w} / \mathbf{v} \%$ & 6 & 54 \\
\hline $\mathbf{2 0} \mathbf{w} / \mathbf{v} \%$ & 12 & 48 \\
\hline
\end{tabular}

\section{Discussion}

\subsection{Preparation of Powdered Cellulose Fibers of Meranti Wood and Betung bamboo}

Cellulose fibers can be synthesized from wood or bamboo powder by adding a solution of sodium chloride and acetic acid to remove the lignin content. Lightning are not regular, random, and a major constituent of the aromatic compounds, which increase the elasticity matrix of cellulose and hemicellulose. As a result of this complexity lignin cellulose is a component that is hard to be broken. This is because the crystal structure of lignin is higher than the cellulose and hemicellulose. Lightning is an undesirable component in the process, beside disrupting the performance of the enzyme; lining also because behind the cellulose bonds result in an increased number of needs enzymes used for hydrolysis. Aim the addition of $\mathrm{KOH}$ for eliminating hemicellulose.

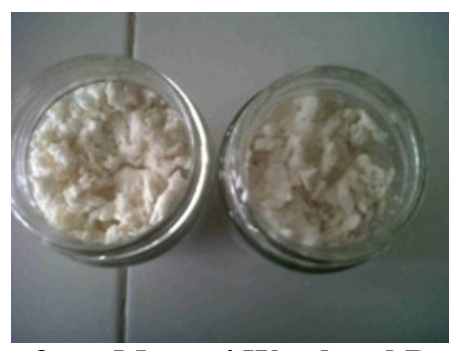

Fig 1. Cellulose Fibers from Meranti Wood and Betung Bamboo

PLA is flexibility enhanced by mixing with cellulose fibers. The mixing process of the PLA and cellulose fibers using an ethanol solution to remove water content contained in the cellulose fibers which subsequent addition of acetone has been used to dissolve the PLA since PLA soluble in organic solvents.

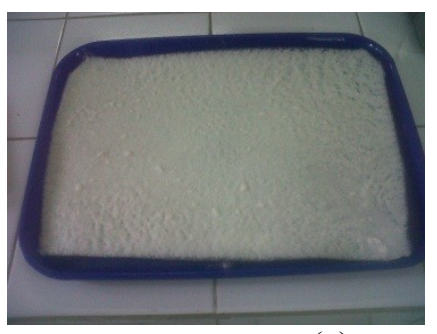

(a)

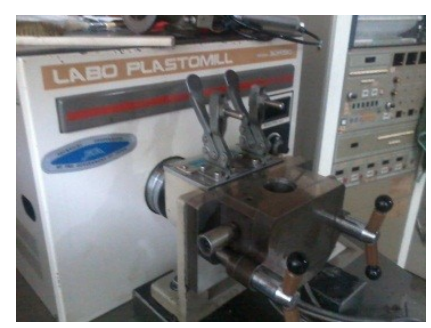

(b) 


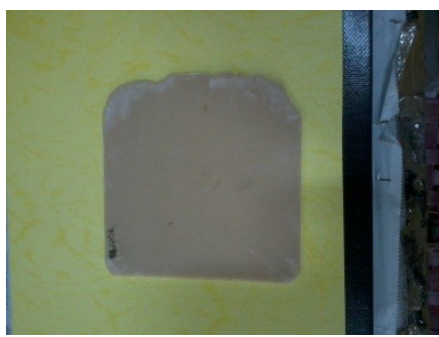

(c)

Fig 2. Mixture of PLA and cellulose fiber (a), labo plastomill (b), the composite is formed (c)

\subsection{Silica modified}

Silica sand is used for the modification of poly lactic acid in characterization using a X-ray fluorescence spectrometer (XRF). This method is a method of analysis of a material nature does not destroy the (nondestructive). X-ray source used to radiate the sample and choose the elements in the sample issued the $\mathrm{X}$-ray characteristics they have. When an element is shot by the x-rays, the radiation characteristic will be issued as a form of energy that will be used in the transfer of electrons from one orbital to another orbital. The primary beam of tube (tube) x-rays cause luminescence characterized by straight lines of the elements contained in a sample. A level of Silica in the silica sand was $223949 \mathrm{ppm}$.

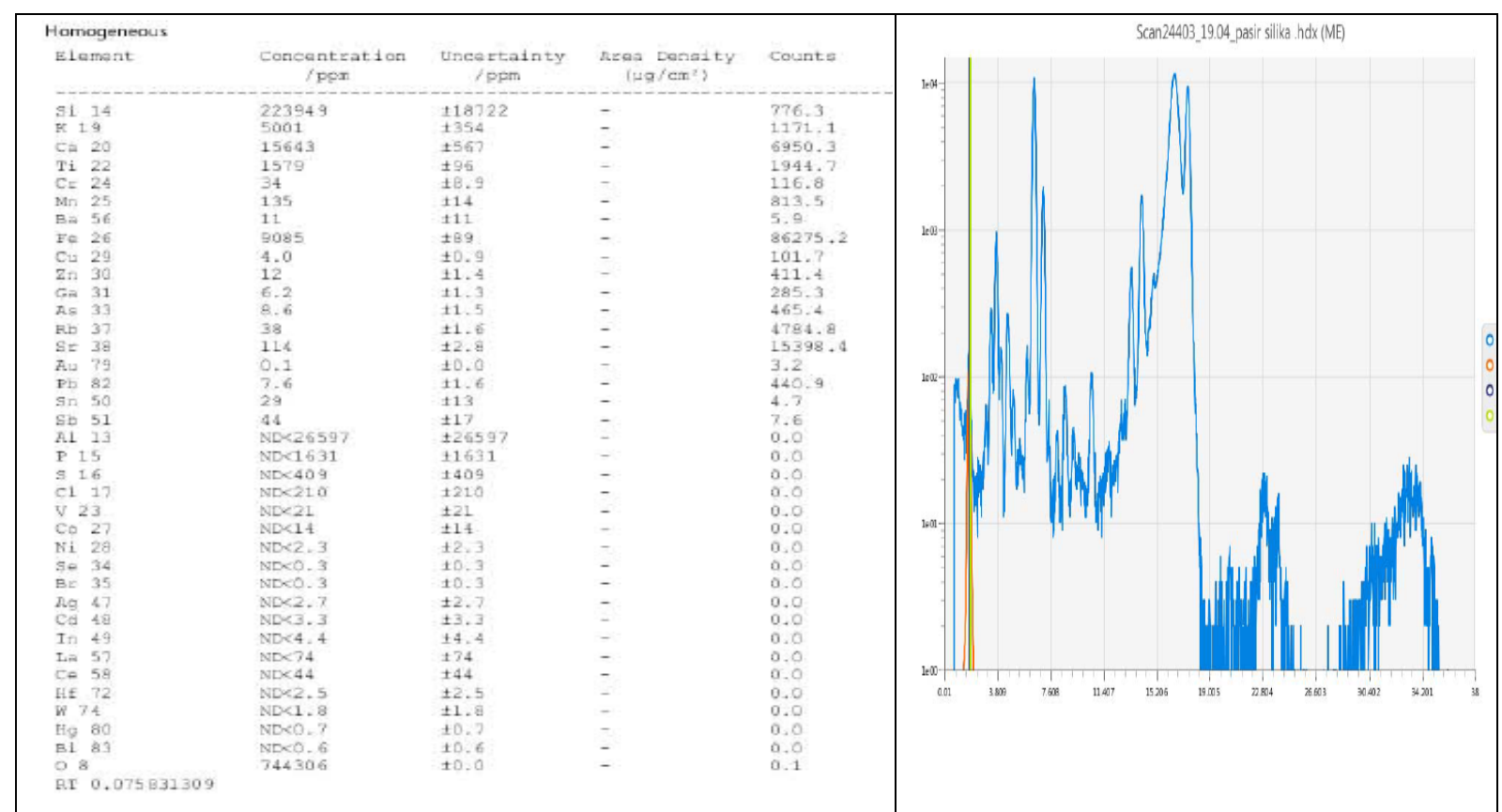

Fig 3. using x-ray Fluorescence spectrometer of silica sand

\subsection{Characterization of Cellulose Fibers}

Cellulose is obtained as cotton and white. To determine whether the cellulose fibers which have been obtained properly containing cellulose fibers then determine group functions using FTIR. Spectrum FTIR results shown in Figure 2 (a) and (b), each having peaks at certain wave numbers. The wave numbers can be seen in Table 2. At Meranti wood and Betung bamboo have nearly the same wave numbers and produce nearly the same peak. On absorption wave numbers $3400 \mathrm{~cm}^{-1}, 2900 \mathrm{~cm}^{-1}, 1635 \mathrm{~cm}^{-}, 1429 \mathrm{~cm}^{-1}$ are $\mathrm{OH}, \mathrm{CH}, \mathrm{C}=\mathrm{O}_{\text {and } \mathrm{CH}_{3}}$ aliphatic compound. The functional group from cellulose chain at Meranti wood and Betung bamboo are hydroxyl. Group-OH can interact with each other with the-O, $-\mathrm{N}$, and-S, forming hydrogen bonds. $-\mathrm{H}$ bonds also occur between the-OH groups of cellulose with water. Cellulose-OH groups cause a hydrophilic cellulose surface. Cellulose chain has a-H group at both ends. End-C1 has reducing properties. The cellulose chain structure is stabilized by strong hydrogen bonds along the chain. In the nature of plant cellulose, cellulose chains are tied together to form micro fibrils highly crystallized (highly crystalline) cellulose chains in which each tied together by hydrogen bonds. 


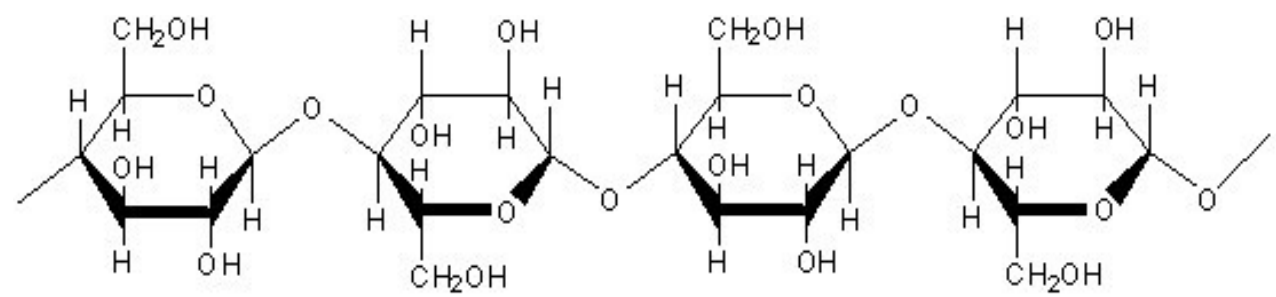

Fig 4. Molecular structure of cellulose

Table 2. The wave numbers at Meranti wood and Betung bamboo

\begin{tabular}{|c|c|c|}
\hline \multirow{2}{*}{ Vibration } & \multicolumn{2}{|c|}{ Wavenumber $\mathbf{( c m}^{-1}$ ) } \\
\cline { 2 - 3 } & Meranti wood & Betung bamboo \\
\hline $\mathbf{O}-\mathbf{H}$ & 3402.22 & 3433.36 \\
\hline $\mathbf{C}-\mathbf{H}$ aliphatic & 2901.06 & 2917.56 \\
\hline $\mathbf{C}=\mathbf{O}$ & 1634.66 & 1635.80 \\
\hline $\mathbf{C H}_{\mathbf{3}}$ & 1429.61 & 1432.56 \\
\hline
\end{tabular}

Fiber alignment greatly affects the tensile and flexion strength, the smaller the fiber direction $\alpha$ to the load imposed on the composite, the greater its power and increase as the volume fraction of filler in the composite fibers with polyester resin can improve the tensile strength and Bending test carried out using Universal Testing Machine (UTM). On the flexible strength testing in lab created special conditions of the test sample is designed as Figure 5. Sample design for flexible test results will be obtained from the data loading. The data from the test obtain equation the bending stress. The maximum bending stress is symbolized by the MOR (Modulus of Rupture). From Figure 5 apparently the flexible strength of the composite KM between 10\% and $20 \%$ there was no significant difference, In contrast to the composition of the bio composite between $10 \%$ and $20 \%$. Flexion strength has the height values contained in the bio composite Betung Bamboo $20 \%$ of $57.4054 \mathrm{~N} / \mathrm{mm} 2$. Tensile Test, many engineering tension test is performed to complete the design of the basic information and the strength of a material as supporting data for material specifications. In the tensile test, the specimen is subjected to load a coaxial tensile force increase continuously, along with the observation of the extension of the specimen experienced. Engineering stress strain curve obtained from the measurement of the extension of the test specimen. Bio composite tensile and flexible strength test is done using UTM. The data from tensil test are shown in figure 6.

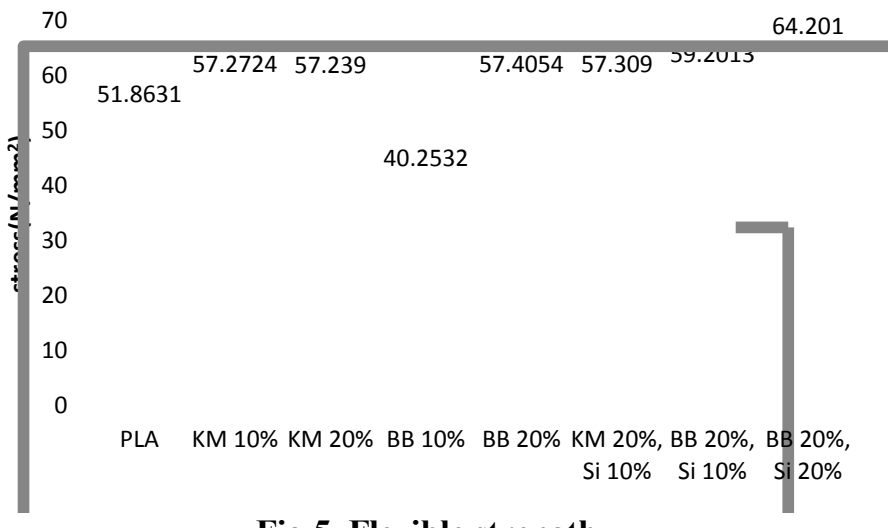

Fig 5. Flexible strength

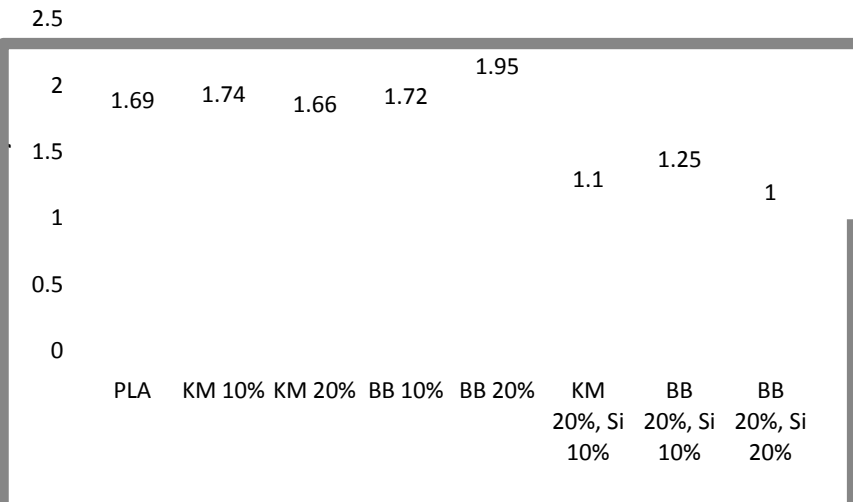

Fig6 .Result Data of Tensile Test from PLA, PLA composite Meranti wood, and Betung bamboo 
Tensile Yield Break elongation modulus apparently the highest power of elasticity found in the composition of the bio composite Betung bamboo $20 \%$ of 1.95 GPA. Addition of silica sand is high strength reinforced silica matrix composite.

FTIR analysis is used to determine the functional groups that are formed from the resulting samples. FTIR spectra were measured with a FTIR Perkin Elmer. The test sample is crushed to powder form and was evaluated by engineering $\mathrm{KBr}_{2}$ pellets, then measured the transmission or absorbent.

In this study, FTIR analysis for determination functional groups of cellulose fibers on Meranti wood and Betung bamboo, FTIR spectrum is the result shown in Figure 7. Spectrum is shown in In the absorption spectrum of the PLA are the C-H stretching appear in wavenumber $2900 \mathrm{~cm}^{-1}$, group C $=\mathrm{O}$ (carbonyl) at 3200 wave numbers where overtone and carbonyl groups experienced wave length 1700 on the carbonyl group and the experience stretching wave numbers 1300 and 1500 are $\mathrm{C}-\mathrm{O}-\mathrm{C}$ group and $\mathrm{CH}_{3}$. For cellulose $\mathrm{KM}$ and $\mathrm{BB}$ have nearly the same wave numbers and produces a peak in the spectrum is almost the same due to the bio composite compounds are the same, namely cellulose and PLA. However, the only difference being the absorbance values for the color of bamboo bio composite Betung bamboo is turbid than the Meranti wood.

(a)

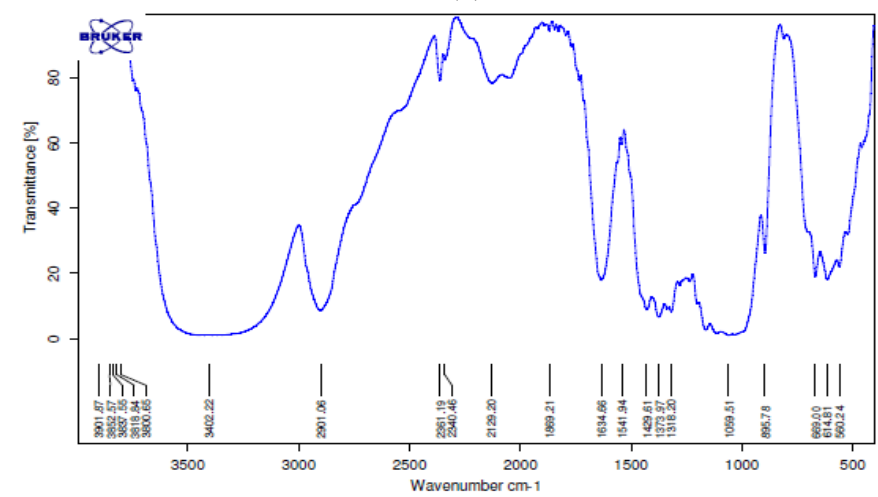

(b)

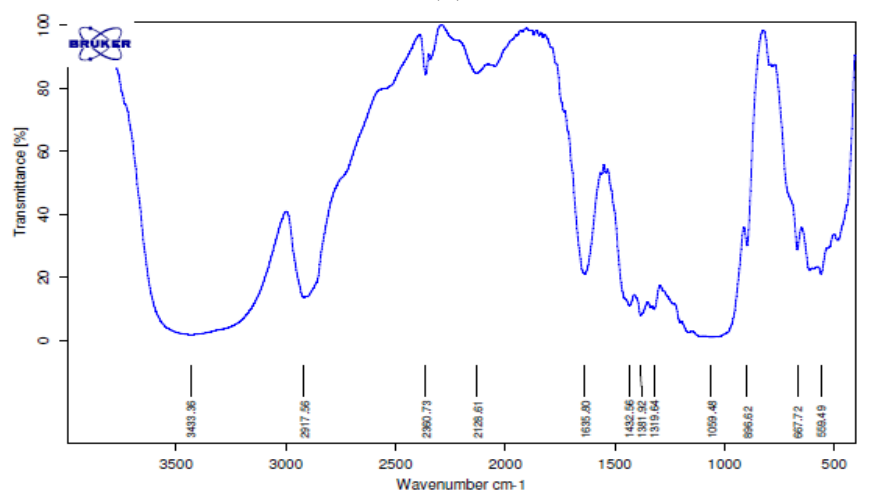

(c)

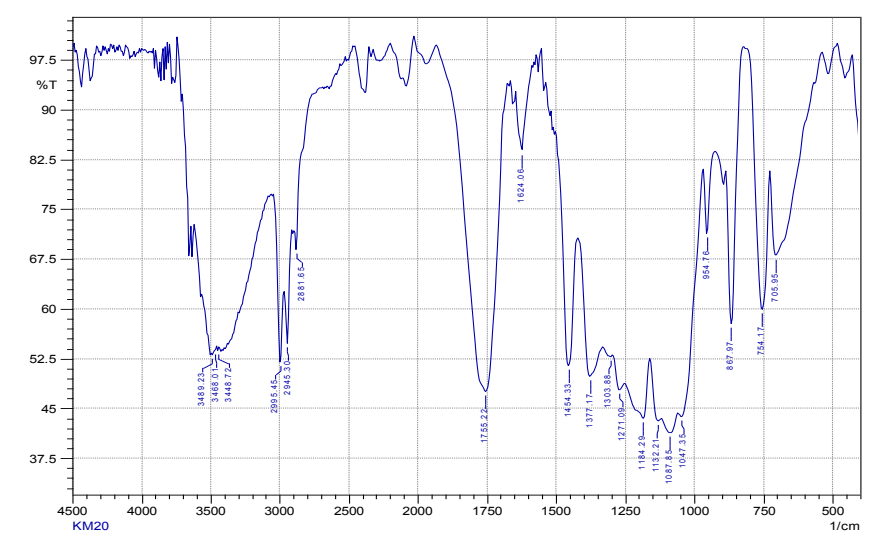

(d) 


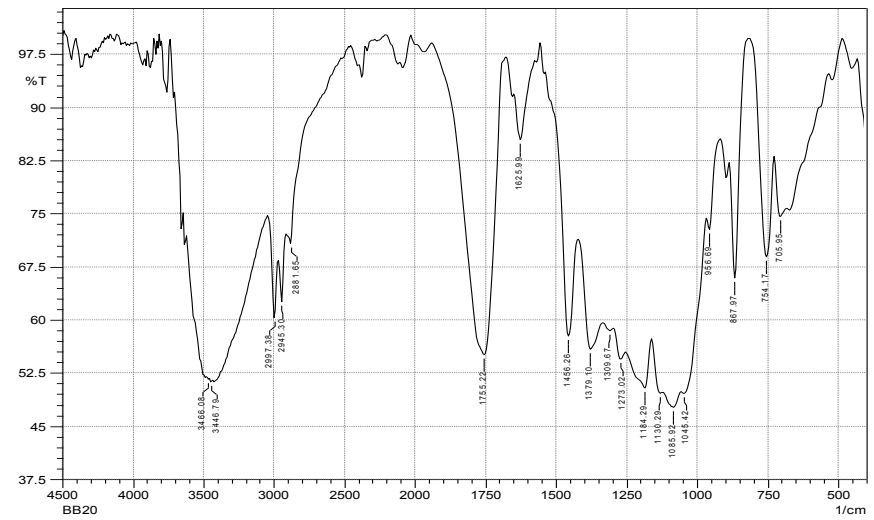

(e)

Fig 7. Spectrum of PLA (a), Meranti wood cellulose fiber (b), Betung bamboo cellulose fiber (c), bio composite KM (d), bio composite BB (e).

Cellulose is obtained as cotton and white. To decide whether the cellulose fibers which have been obtained properly containing cellulose fibers then determine group functions using FTIR. Spectrum FTIR results shown in Figure 2 (a) and (b), each having peaks at certain wave numbers. The wave numbers can be seen in Table 3. At Meranti wood and Betung bamboo have nearly the same wave numbers and produce nearly the same peak. On absorption wave numbers $3400 \mathrm{~cm}^{-1}, 2900 \mathrm{~cm}^{-1}, 1635 \mathrm{~cm}^{-1}, 1429 \mathrm{~cm}^{-1}$ there are $\mathrm{OH}, \mathrm{CH}, \mathrm{C}=\mathrm{O}$ and $\mathrm{CH}_{3}$ aliphatic compound. The functional group from cellulose chain at Meranti wood and Betung bamboo are hydroxyl. Group-OH can interact with each other with the- $\mathrm{O},-\mathrm{N}$, and-S, forming hydrogen bonds. - $\mathrm{H}$ bonds also occur between the-OH groups of cellulose with water. Cellulose-OH groups cause a hydrophilic cellulose surface. Cellulose chain has a-H group at both ends, $-\mathrm{C} 1$ has reducing properties. The cellulose chain structure is stabilized by strong hydrogen bonds along the chain. In the nature of plant cellulose, cellulose chains are tied together to form micro fibrils highly crystallized (highly crystalline) cellulose chains in which each tied together by hydrogen bonds.

Tabel 3. Functional Group Meranti wood and Betung bamboo in PLA Composite

\begin{tabular}{|c|c|c|c|c|c|c|c|}
\hline \multirow[t]{2}{*}{ Vibration } & \multicolumn{7}{|c|}{ Wavelength $\left(\mathrm{cm}^{-1}\right)$} \\
\hline & PLA & $\begin{array}{c}\text { cellulose } \\
\text { KM }\end{array}$ & $\begin{array}{c}\text { cellulose } \\
\text { BB }\end{array}$ & $\begin{array}{l}\text { Bio } \\
\text { composite } \\
\text { KM 10\% }\end{array}$ & $\begin{array}{l}\text { Bio } \\
\text { composite } \\
\text { KM 20\% }\end{array}$ & $\begin{array}{l}\text { Bio } \\
\text { composite }\end{array}$ & $\begin{array}{l}\text { Bio } \\
\text { composite } \\
\text { BB 20\% }\end{array}$ \\
\hline $\mathrm{OH}$ & - & 3402 & 3433 & 3485 & 3489 & 3487 & 3466 \\
\hline $\begin{array}{c}\mathrm{C}-\mathrm{H} \\
\text { stretching }\end{array}$ & 2900 & 2901 & 2917 & 2995 & 2995 & 2997 & 2997 \\
\hline $\mathrm{C}=\mathrm{O}$ & $\begin{array}{c}3200 \\
\text { dan } \\
1700\end{array}$ & 1634 & 1635 & 1755 & 1755 & 1755 & 1755 \\
\hline $\begin{array}{c}\text { C-O-C } \\
\text { Stretching }\end{array}$ & 1300 & 1373 & 1381 & 1379 & 1377 & 1377 & 1379 \\
\hline $\begin{array}{c}\mathrm{CH}_{3} \\
\text { bending }\end{array}$ & 1500 & 1429 & 1432 & 1454 & 1454 & 1456 & 1458 \\
\hline
\end{tabular}

The IR spectrum for $10 \%$ and $20 \%$ of silica modified shows the carbonyl stretching vibration at 513.07 $\mathrm{cm}^{-1}$ and $511,14 \mathrm{~cm}^{-1}$ this indicates that $\mathrm{Si}-\mathrm{OH}$ groups. $956.69 \mathrm{~cm}^{-1}$ and $920.05 \mathrm{~cm}^{-1}$ indicate si-O-Si and $3853.18 \mathrm{~cm}^{-1}$ indicate the existence of the cluster $-\mathrm{OH}$. 


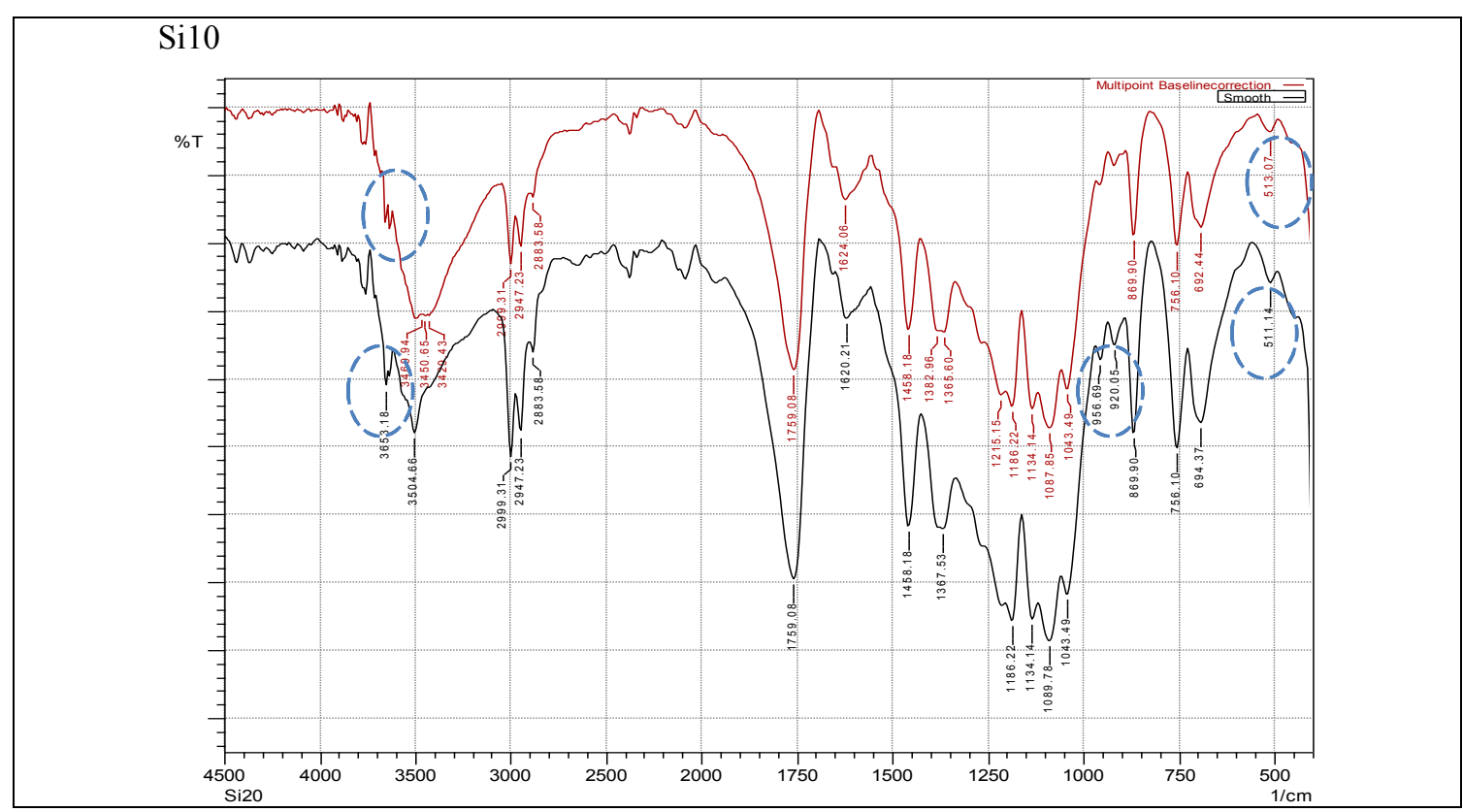

Fig 8. Spectrum of PLA-selulosa bamboo with silica modified

The IR spectrum for $10 \%$ and $20 \%$ of silica modified shows the carbonyl stretching vibration at 513.07 $\mathrm{cm}^{-1}$ and $511,14 \mathrm{~cm}-1$ this indicates that Si-OH groups. $956.69 \mathrm{~cm}^{-1}$ and $920.05 \mathrm{~cm}^{-1}$ indicates si-O-Si and $3853.18 \mathrm{~cm}^{-1}$ indicate the existence of the cluster $-\mathrm{OH}$.

\subsection{SEM/EDX Image}

Energy-dispersive x-ray spectroscopy is used for the elemental analysis or chemical characterization of a sample. It relies on the investigation of an interaction of some source of $\mathrm{x}$-ray excitation and a sample. Its characterization capabilities are due in large part to the fundamental principle that each element has an unique atomic structure allowing an unique set of peaks in its x-ray spectrum. Based on the results of the EDX on PLA Betung bamboo consists of carbon 43, 27\% and oxygen 56.28\%. Results of EDX PLA with Betung bamboo and silica sand as a modifier composing the element carbon.

(a)
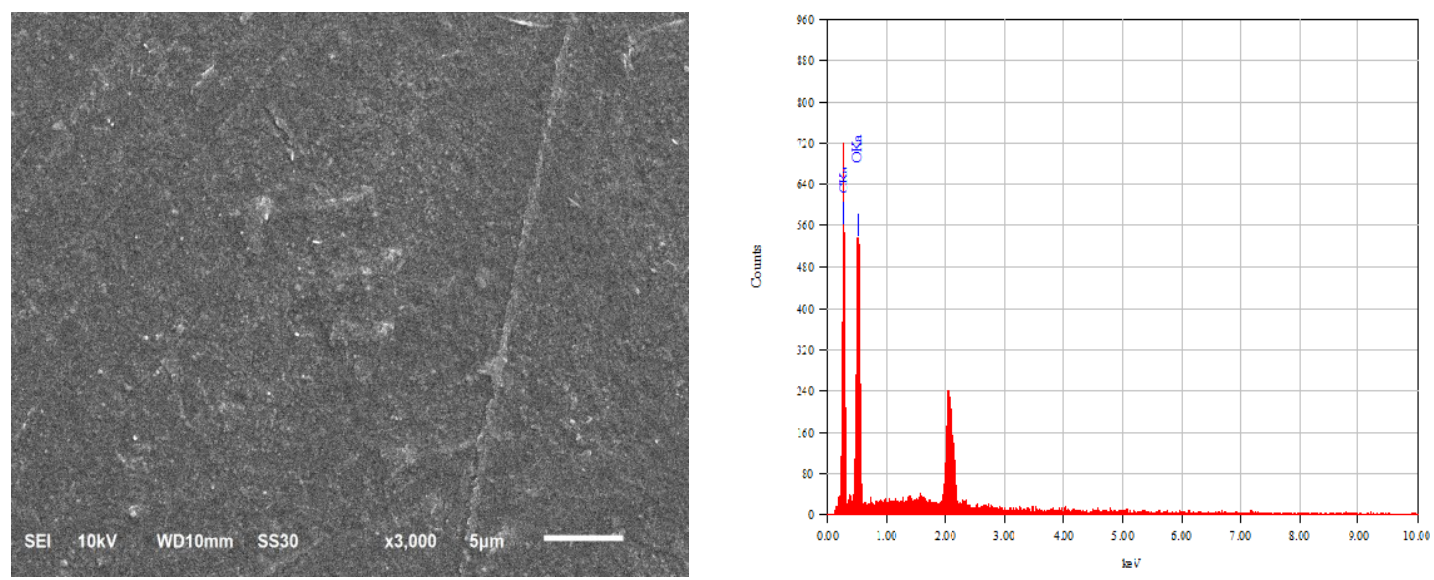
(b)
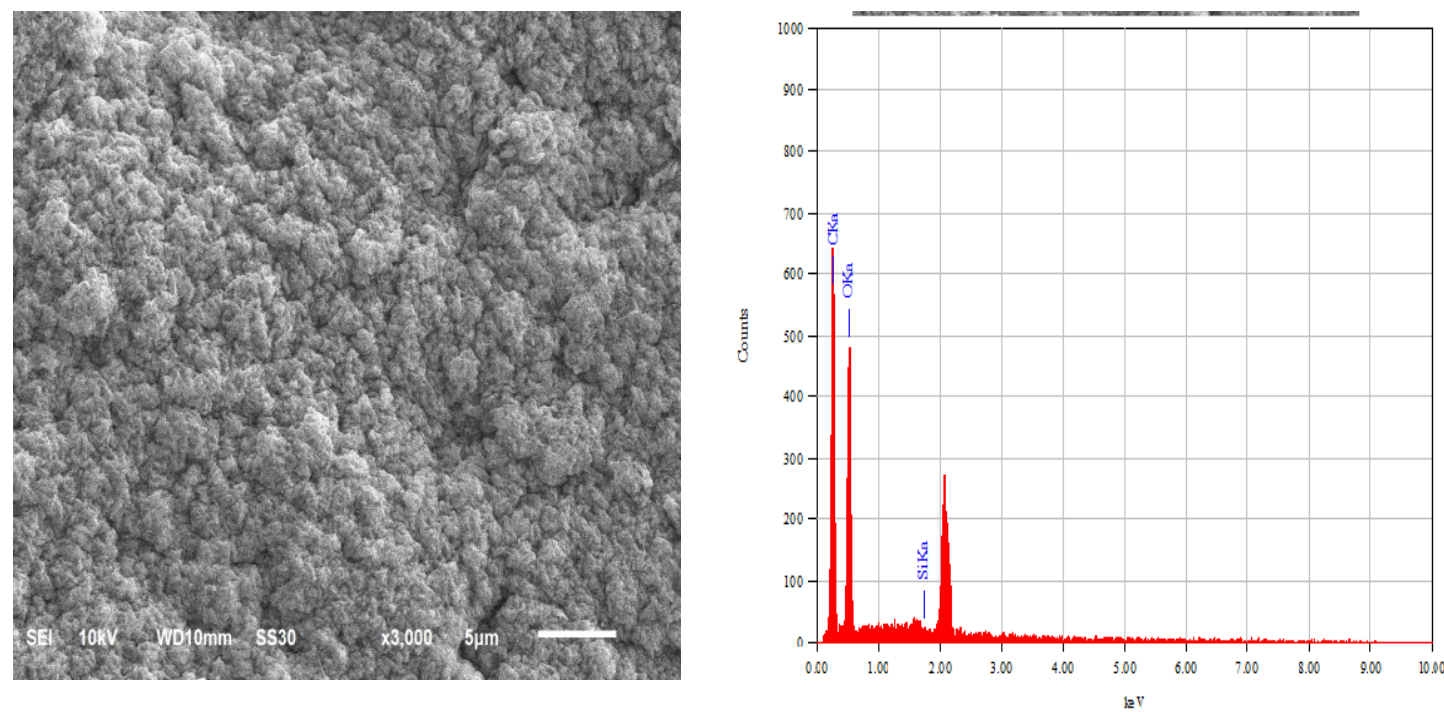

Fig 8. SEM/EDX image for composite PLA, unmodified silica sand (a), modified silica sand(b)

\section{Conclusion}

Composites can be made by mixing cellulose fibers from Meranti wood or Betung bamboo with PLA matrix so that there are better mechanical properties. Bending stress and tensile strength is highest at $20 \%$ between bamboo for composite PLA of $57.4054 \mathrm{~N} / \mathrm{mm}^{2}$ and 1.95 GPA. Betung bamboo is high strength reinforced silica matrix composite.

\section{Reference}

[1] Zimmerman, T., Pohler, E., Geiger, T. "Cellulose fibrils for polymer reinforcement. Advanced Engineering Science", Advanced Engineering Material, Vol. 6(9), pp.754-761, 2004.

[2] Abe K, Iwamoto S, Yano H, "Obtaining cellulose Nano fibers with a uniform width of $15 \mathrm{~nm}$ from wood", Bio macromolecule, vol.8, pp.3276-3278, 2007 .

[3] Esmeralda U.L, Maria Gabriel, Victor Geraldo, Alejandra, "Determination of mechanical properties of Biodegradable Composite made by Pine Resin Corn Fibers and Henequen Fiber" Engineering Material, Vol. 517, pp. 422-429, 2012.

[4] Abdurahim, M. 1986. Wood description. Department of Forestry Agency for Forestry and Development Forest Product Research Development Centre. Bogor Indonesia. Hal 81-87

[5] Rafael Auras, Leong Tak Lim, Susan Em Seiko, Hideto Tsuji, "Poly lactic acid: synthesis, properties and processing application". Willey, ISBN 8780770293669, 2010.

[6] Pandey, K. Raghunatha Reddy, A. Patheep Kumar, P.P Sing, "Degradability of polymer composite from renewable resources", International journal of Polymer Degradation and Stability, elsivier, vol 88, pp.234-250, 20005

[7] Paul A Fowler, J Mark Hughes, and Robert M Elias, "Bio composites: technology, environmental credentials and market forces". Journal of the Science of Food and Agricultural, vol 86, pp. 1781-1789, 2006.

[8] Suryanegara, L., Nakagaito, A.N., Yano, H. The effect of crystallization of PLA on the thermal and mechanical properties of micro fibrillated cellulose- reinforced PLA composites. Composites science and Technology 69:1187-1192, 2009. 